This is an open access article distributed under the terms of the Creative Commons BY-NC-ND Licence

\title{
Rosmarinic acid accumulation in Melissa officinalis shoot cultures is mediated by ABA
}

\author{
S.-M. MOUSAVI and L. SHABANI* \\ Department of Biology, Faculty of Sciences, Shahrekord University, Shahrekord, 8818634141, Iran
}

\begin{abstract}
Plant responses to elicitors are the result of a series of highly modulated consecutive changes in hormones or reactive oxygen species (ROS). Abscisic acid (ABA) is a stress hormone that coordinates the complex networks of stress responses and its content is rapidly changed in response to stresses. This study evaluated the effects of application of ABA $(0,5$, 25, 50, and $100 \mu \mathrm{M}$ ) to shoot cultures of lemon balm (Melissa officinalis L.) in Murashige and Skoog (MS) liquid medium on growth, $\mathrm{H}_{2} \mathrm{O}_{2}$ production, rosmarinic acid (RA) content, total phenolic compound accumulation, phenylalanineammonia lyase $(P A L)$ gene expression, and PAL activity. Our results showed that all the applied concentrations of ABA decreased the growth rate of shoots. Moreover, the expression of $P A L$, tyrosine aminotransferase (TAT), and rosmarinic acid synthase $(R A S)$ genes, PAL activity, and the accumulation of total phenolic compound as well as RA were increased in the ABA-treated shoots. The highest content of RA was detected in the shoots treated with $100 \mu \mathrm{M}$ ABA. The results suggested that both the PAL- and TAT-derived pathways were induced by ABA to increase RA accumulation in the shoot cultures of lemon balm. The results revealed that application of ABA led to up-regulation of respiratory burst oxidase homolog $(\mathrm{RBOH})$ expression, which was correlated with the production of $\mathrm{H}_{2} \mathrm{O}_{2}$ in the shoots cultures. In addition, the cis epoxy carotenoid dioxygenase (NCED) gene, which encodes key enzyme involved in ABA biosynthesis was upregulated. These results demonstrated that ABA treatment enhanced endogenous ABA content and rosmarinic acid synthesis in the shoot cultures of lemon balm.
\end{abstract}

Additional key words: 9-cis epoxy carotenoid dioxygenase, lemon balm, phenylalanine-ammonia lyase, rosmarinic acid synthase, tyrosine aminotransferase.

\section{Introduction}

Rosmarinic acid (RA) is an ester of caffeic acid and 3,4-dihydroxyphenyllactic acid. As a main active phenolic compound, it is commonly found in species of the subfamily Nepetoideae of the Lamiaceae, including perilla, rosemary, sage, mint, basil, and lemon balm (Melissa officinalis L.). The RA shows antiviral, antibacterial, anti-inflammatory, hepatoprotective, antiangiogenic, antidepressant, antineurodegenerative, antiallergic, and antioxidant activities (Petersen and Simmonds 2003). The biosynthesis of rosmarinic acid has been vastly investigated for two reasons: 1) rosmarinic acid has been shown to be a useful compound in the field of medicine, and as a food additive, 2) accumulated RA contributes to the defense against microbes. Moreover, the challenge to elucidate the compelling biosynthesis of RA which consists of two parallel biosynthetic pathways that should be regulated in a coordinated way is one of the other reasons for extensive studying of rosmarinic acid (Matsuno et al. 2002). Additionally, rosmarinic acid can be accumulated in plants as a defensive compound and protection against herbivores.

The initial report on the biosynthetic route of rosmarinic acid has demonstrated the involvement of two aromatic amino acids, L-tyrosine (tyrosine-derived pathway) and L-phenylalanine (phenylpropanoid pathway) (Ellis and Towers 1970). A coumaroyl-CoA is derived from phenylalanine in three well characterized enzymatic steps catalyzed by phenylalanine-ammonialyase (PAL), cinnamic acid 4-hydroxylase $(\mathrm{C} 4 \mathrm{H}$,$) and$ 4-coumaric acid-CoA ligase (4CL). The second pathway

Submitted 7 August 2018, last revision 11 October 2018, accepted 5 November 2018.

Abbreviations: ABA - abscisic acid; MS - Murashige and Skoog; NCED - 9-cis epoxy carotenoid dioxygenase; PAL - phenylalanineammonia lyase; RA - rosmarinic acid; RAS - rosmarinic acid synthase; RBOH - respiratory burst oxidase homolog; ROS - reactive oxygen species; TAT - tyrosine aminotransferase.

Acknowledgment: The authors are grateful for the grant from Shahrekord University No. 94GDR1M1032.

* Corresponding author; fax: (+981) 3814424419, e-mail: shabani-1@sci.sku.ac.ir 
originates from tyrosine which results in the formation of 4-hydroxyphenyllactate (4HPL). Tyrosine aminotransferase (TAT) is the first enzyme in the tyrosine-derived branch of RA biosynthesis. The two ingredients of the parallel pathways, i.e, caffeoyl-CoA and 3,4-dihydroxyphenyllactic acid (DHPL) are connected by rosmarinic acid synthase (RAS) catalyzing a transesterification reaction (Petersen 1991). Kim et al. (2013) have pointed out that addition of methyl jasmonate (MJ) into cell suspension culture of Agastache rugosa rapidly induced PAL but not TAT activity during RA accumulation. Similar results have been reported by Mizukami et al. (1992) who elicited the Lithospermum erythrorhizon cell suspension cultures by yeast extract. Conversely, some other reports have demonstrated that elicitors induced biosynthesis of RA and phenolic compounds in Salvia miltiorrhiza hairy roots, which was correlated with tyrosine-derived pathway (Yan et al. 2006).

The production of phenolic secondary metabolites can be maximized by elicitors, such as MJ, salicylic acid (SA), ABA, polyamines, metal ions, $\mathrm{H}_{2} \mathrm{O}_{2}$, UV-B, and yeast extracts (Ma et al. 2013). Plants respond to elicitor due to a series of highly modulated consecutive changes in their hormones or ROS (reactive oxygen species) (Jabs 1999, Ton et al. 2009). The ABA has been recognized as a stress hormone coordinating the complex networks of stress responses (Zhang et al. 2006). In some plant species, changes in the amount of endogenous ABA may play an important role in the induction of biosynthesis of RA and related phenolic compounds (Vagner et al. 1998, Gagne et al. 2011, Hao et al. 2012, Villalobos-Gonzaalez et al. 2016). Further evidence supports the idea that ABA content is highly modulated by regulation of the different steps of its biosynthesis (Thompson et al. 2007, Rodriguez-Gacio et al. 2009). Several recent studies have investigated the capability of ABA to induce the accumulation of phenolic compound in cell and tissue cultures as well as in field experiments (Gagne et al. 2011, Ibrahim and Jaafar 2013, Liang et al. 2013, VillalobosGonzaalez et al. 2016, Murcia et al. 2017).

The aim of this study was to investigate the effect of ABA on RA accumulation in the shoot cultures of Melisa officinalis in order to reveal the contribution of two metabolic pathways to RA biosynthesis. Further, the correlations between enzyme activities and the expression of corresponding genes were determined.

\section{Materials and methods}

Plants, culture conditions, and ABA treatment: Seeds of Melissa officinalis L. were purchased from Pakanbazr seed company (Isfahan Province, Isfahan, Iran). Seeds were surface sterilized with $70 \%(\mathrm{v} / \mathrm{v})$ ethanol for $20 \mathrm{~s}$ and $20 \%(\mathrm{~m} / \mathrm{v})$ sodium hypochlorite solution for $8 \mathrm{~min}$. Then, they were rinsed five times in sterile distilled water. For germination, seeds were placed in autoclaved hormone free of 1/2 Murashige and Skoog (1962; MS) medium supplemented with $13 \mathrm{~g} \mathrm{dm}^{-3}$ sucrose and $0.7 \%(\mathrm{~m} / \mathrm{v})$ agar. After germination, seedlings were maintained in a growth chamber (Binder, Tuttlingen, Germany) at a temperature of $25 \pm 1{ }^{\circ} \mathrm{C}$, a 16 -h photoperiod, and an irradiance of $650 \mu \mathrm{mol} \mathrm{m} \mathrm{m}^{-2} \mathrm{~s}^{-1}$. After one month, plantlets were subcultured using the same medium and conditions. The shoots $(5 \mathrm{~cm}$ length with 3 nodes) were excised from 60 -d-old sterile seedlings and were cultured on hormone free liquid 1/2 MS medium supplemented with various concentrations $(0,5,25,50$ and $100 \mu \mathrm{M})$ of ABA. Stock solution of $( \pm$-abscisic acid (Sigma, Steinheim, Germany) was prepared by dissolving certain amounts of ABA in methanol. The same volume of methanol was added to the control shoot cultures. During the experiment, shoot cultures were maintained on an orbital shaker (110 rpm) (Lab Tech, Seoul, South Korea) at conditions mentioned above. The shoots were harvested 7 and $14 \mathrm{~d}$ after ABA treatment. Gene expression analysis, $\mathrm{H}_{2} \mathrm{O}_{2}$, and ABA content were performed on day 7. Shoot fresh mass, total phenolic compound, rosmarinic acid content, and PAL activity were recorded two weeks after elicitation.
$\mathrm{H}_{2} \mathrm{O}_{2}$ assay: The content of $\mathrm{H}_{2} \mathrm{O}_{2}$ was measured according to Alexieva et al. (2001). Fresh shoot tissue $(0.1 \mathrm{~g})$ was macerated in $1.5 \mathrm{~cm}^{3}$ of $0.1 \%(\mathrm{~m} / \mathrm{v})$ trichlotoacetic acid (TCA). After centrifugation $\left(12000 \mathrm{~g}, 4{ }^{\circ} \mathrm{C}, 15 \mathrm{~min}\right)$, $0.5 \mathrm{~cm}^{3}$ of the supernatant was then mixed with $0.5 \mathrm{~cm}^{3}$ of $10 \mathrm{mM}$ potassium phosphate buffer $(\mathrm{pH} \mathrm{7})$ and $1 \mathrm{~cm}^{3}$ of $1 \mathrm{M}$ KI. The absorbance of mixture was measured at $390 \mathrm{~nm}$ using a UV/Vis spectrophotometer (Ultrospec ${ }^{\mathrm{TM}}$ 3100 pro, GE Healthcare Life Sciences, Pittsburgh, USA). Results were calculated with help of a $\mathrm{H}_{2} \mathrm{O}_{2}$ standard curve.

Total phenolic and rosmarinic acid content: Total phenolic content was quantified using Folin-Ciocalteu assay (Singleton and Rossi 1965). Plant tissue (0.1 g) was homogenized in $3 \mathrm{~cm}^{3}$ of extraction buffer containing $80 \%(\mathrm{v} / \mathrm{v})$ methanol in a pre-chilled mortar. The homogenate was centrifuged at $15000 \mathrm{~g}$ for $15 \mathrm{~min}$. In reaction test tube, $0.02 \mathrm{~cm}^{3}$ of the sample extract was mixed with $0.12 \mathrm{~cm}^{3} 20 \%(\mathrm{~m} / \mathrm{v}) \mathrm{Na}_{2} \mathrm{CO}_{3}$ and $0.15 \mathrm{~cm}^{3}$ of Folin-Ciocalteu reagent. After $30 \mathrm{~min}$ at dark and room temperature, absorbance was measured measure at 765 $\mathrm{nm}$. Total phenolic content was expressed as $\mathrm{mg}$ of gallic acid per $\mathrm{g}$ of fresh mass.

Rosmarinic acid extraction and analysis followed the methods described by Öztürk et al. (2010). Methanol extract of shoots $\left(0.2 \mathrm{~cm}^{3}\right)$ was added to $0.2 \mathrm{~cm}^{3}$ of $0.5 \mathrm{M}$ $\mathrm{ZrOCl}_{2} .8 \mathrm{H}_{2} \mathrm{O}$ and $4.6 \mathrm{~cm}^{3}$ of ethanol. After $5 \mathrm{~min}$, the absorbance of reaction mixture was measured at $362 \mathrm{~nm}$. 
Rosmarinic acid (Sigma) at the range of $0-0.004 \mathrm{mM}$ was used as a standard.

PAL activity analysis: PAL activity was assayed according to Abell and Shen (1987). The reaction mixture contained $2.5 \mathrm{~cm}^{3}$ of $0.1 \mathrm{M}$ Tris- $\mathrm{HCl}(\mathrm{pH} 8.5)$ with $12 \mathrm{mM}$ phenylalanine and $0.5 \mathrm{~cm}^{3}$ of enzyme extract. The reaction mixture without phenylalanine was added as controls. At the onset of reaction and an hour later, increase in absorbance due to PAL activity was recorded at $290 \mathrm{~nm}$. One unit was defined as the amount that caused an increase of 0.01 in the absorbance per h.

HPLC analysis of ABA content: Quantification of ABA was performed using an HPLC system (Waters, Massachusetts, USA) based on the methods of Kelen et al. (2004) with slight modifications. For extraction of ABA, $1 \mathrm{~g}$ of fresh shoots was homogenized with $10 \mathrm{~cm}^{3}$ of $80 \%$ (v/v) methanol containing butylated hydroxytoluen and ascorbic acid and stirred overnight at $4{ }^{\circ} \mathrm{C}$. The extract was filtered through a Whatman filter paper and the methanol was evaporated under vacuum at $-35^{\circ} \mathrm{C}$. The residue was dissolved in $0.5 \mathrm{M}$ potassium phosphate buffer, and adjusted to $\mathrm{pH} 8.5$ with $0.2 \mathrm{M} \mathrm{KOH}$. The ethyl acetate was added in volume equal to volume of mixture. The solution was vortexed and the ethyl acetate phase was discarded and the remaining ethyl acetate was freeze dried by evaporating at $-35^{\circ} \mathrm{C}$. The $\mathrm{pH}$ of the aqueous phase was adjusted to 2.5 with $0.2 \mathrm{M} \mathrm{HCl}$. The residue was dissolved in ethyl acetate, and the extract was evaporated under vacuum to remove ethyl acetate. The dry residue was dissolved in $0.5 \mathrm{~cm}^{3}$ of methanol and filtered through a $0.22 \mu \mathrm{m}$ membrane and stored at $-80^{\circ} \mathrm{C}$ until analysis. The samples $\left(0.02 \mathrm{~cm}^{3}\right)$ was injected into a reverse-phase column $(\mathrm{C} 18,250 \times 4.6 \mathrm{~mm})$. The mobile phase consisted of acetic acid $(0.2 \%)$ and methanol $(100 \%)(50: 50, \mathrm{v} / \mathrm{v})$, and the flow rate was $0.7 \mathrm{~cm}^{3} \mathrm{~min}^{-1}$. Apparatus wavelength was adjusted to $265 \mathrm{~nm}$. Identification of unknown peaks was based on retention time and UV absorption spectral comparison with known standards of $( \pm)$-ABA.

RNA extraction and cDNA synthesis: RNAs were extracted by DENAzist kit (DENAzist Asia Co., Mashhad, Iran) from fresh leaves according to manufacturer's instructions. The recombinant DNase I treatment was used to remove contaminating DNA from RNA preparations and RNA (500 ng) was reverse transcribed to first strand cDNA using PrimeScript RT Enzyme Mix I (TaKaRa Bio, Otsu, Japan), which were later used as templates for realtime PCR.

The sequences of the $R A S$ and $P A L$ genes were obtained from the NCBI database (GenBank accession Nos. FR670523.1 and FN665700.1, respectively). The primers of NCED (9-cis epoxy carotenoid dioxygenase) corresponding to conserved regions of NCED were determined using a nucleotide alignment that included NCEDs from a range of plant species: Sesamum indicum (XM-011084544.2), S. indicum (XM-011099822.2), Scutellaria baicalensis (KC760149), Fragaria $\times$ ananassa (JX013945.1), Fragaria vesca (XM-004300619.2), Erythranthe guttatus (XM-012981017.1), and Daucus carota (NM-001329172.1). The primers for Actin and TAT genes were taken from Doring et al. (2014). RNA-seq data (GSE100970) was used for design primers of $R B O H$ gene (NADPH oxidase B).

Real-time quantitative PCR analysis: Relative gene expression was determined by real-time qPCR using a Rotor-Gene $Q$ instrument (Qiagen, Hilden, Germany). The PCR mixture $\left(0.01 \mathrm{~cm}^{3}\right)$ contained $10 \mu \mathrm{M}$ of each primer, $50 \mathrm{ng}$ of the cDNA template and $0.005 \mathrm{~cm}^{3}$ of $S Y B R$ Premix Ex Taq (TaKaRa Bio). The thermal cycle conditions were as follows: pre-incubation at $95{ }^{\circ} \mathrm{C}$ for $10 \mathrm{~min}, 40$ cycles of $95^{\circ} \mathrm{C}$ for $5 \mathrm{~s}, 58-62^{\circ} \mathrm{C}$ for $10 \mathrm{~s}$, and $72{ }^{\circ} \mathrm{C}$ for $20 \mathrm{~s}$. The purity of the amplified products was confirmed by melting curve analysis and agarose gel electrophoresis. All reactions were performed twice.

Data analysis: The data were analyzed by $A N O V A$ in the computer software $S A S$ v. 8. Mean comparisons were performed with the least significant difference (LSD) test.

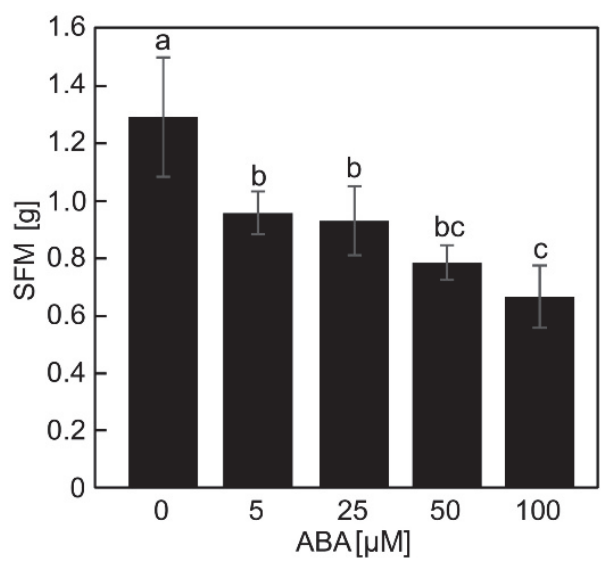

Fig. 1. Effect of different concentrations of abscisic acid (ABA) on fresh mass of Melissa officinalis shoots (SFM) two weeks after application. Means \pm SDs, $n=3$. Values followed by different letters are significantly different at $P \leq 0.05$ according to LSD test.

\section{Results}

The shoots fresh mass (SFM) was significantly affected by $\mathrm{ABA}$ at all applied concentrations with the maximum

reduction in the shoots treated with $100 \mu \mathrm{M}$ of $\mathrm{ABA}$ (Fig. 1). Evaluation of $\mathrm{H}_{2} \mathrm{O}_{2}$ production (Fig. $2 A$ ) indicated 
a significant enhancement of $\mathrm{H}_{2} \mathrm{O}_{2}$ content in all ABAtreated shoots with maximum at the highest ABA concentration. Also, the activity of PAL was increased with increasing ABA concentration (Fig. 2B). The content of phenolic compounds was 1.09-, 3.24-, 1.5-, and 1.7-fold higher in the shoots exposed to $5,25,50$, and $100 \mathrm{mM}$ of ABA, respectively, compared to the control (Fig. 3A). Similarly, rosmarinic acid content was a significantly enhanced in all the ABA-treated shoots compared to the control. The highest content of rosmarinic acid was detected in the shoots treated with $100 \mu \mathrm{M}$ ABA two weeks after elicitation, which was 14 times higher than that of the control (Fig. 3B). One week after elicitation with $50 \mu \mathrm{M}$ of $\mathrm{ABA}$, a 55-fold increase was observed in the endogenous ABA content, which was the maximum amount of ABA detected in the elicited shoots (Fig. 4).

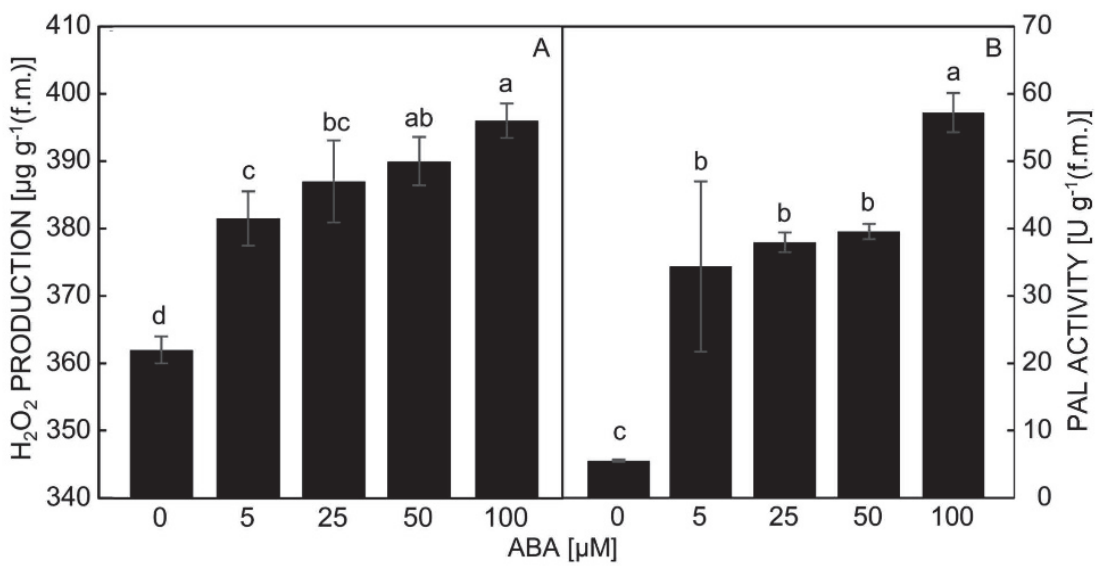

Fig. 2. Effect of different concentrations of ABA on $\mathrm{H}_{2} \mathrm{O}_{2}$ production $(A)$ and PAL activity $(B)$ in Melissa officinalis shoots one weeks after application. Means \pm SDs, $n=3$. Values followed by different letters are significantly different at $P \leq 0.05$ according to LSD test.

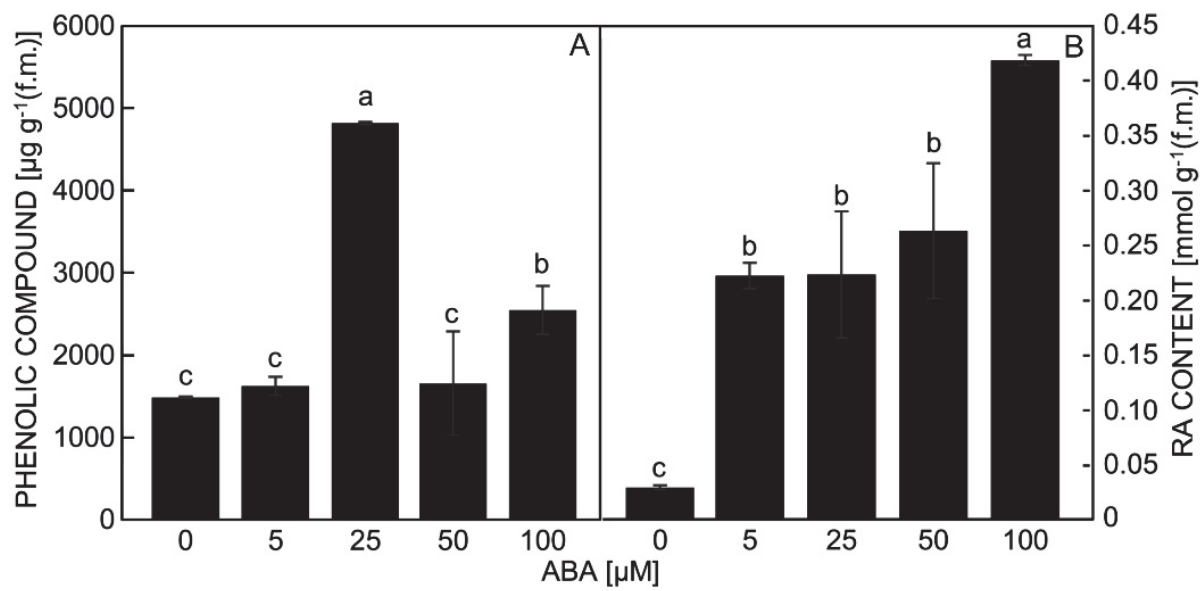

Fig. 3. Effect of different concentrations of ABA on content of phenolic compounds $(A)$ and rosmarinic acid $(B)$ in $M e l i s s a$ officinalis shoots one week after elicitation. Means \pm SDs, $n=3$. Values followed by different letters are significantly different at $P \leq 0.05$ according to LSD test.

The effects of various concentrations of $\mathrm{ABA}$ on expressions of PAL, TAT, RAS, RBOH, and NCED genes were investigated using real-time PCR analysis (Fig. 5). Evaluation of gene expression profile indicated that $P A L$ was significantly up-regulated in all the ABA-treated shoots. The expressions of TAT gene were significantly up-regulated at the ABA concentrations of 25,50 , and
$100 \mu \mathrm{M}$ compared to the control. Moreover, gene expressions of both $R A S$ and $R B O H$ genes were upregulated at all concentrations of ABA compared to the control, but the highest expression of $R B O H$ gene was detected in the shoots treated with $25 \mu \mathrm{M}$ ABA. The expression of NCED gene was significantly up-regulated in the shoots treated with 25 and $50 \mu \mathrm{M}$ of ABA. 


\section{Discussion}

The present study investigated whether ABA-application alters expressions of the genes involved in the biosynthesis of RA and its accumulation in the shoot cultures of lemon balm. ABA is often described as a growth inhibitor since the reduced growth under stress condition is correlated with the increased ABA content; moreover, applied ABA prevents germination and seedling growth (Hedden and Thomas 2006). In this study, substantial differences in growth rate were observed between the ABA-treated and control shoots.

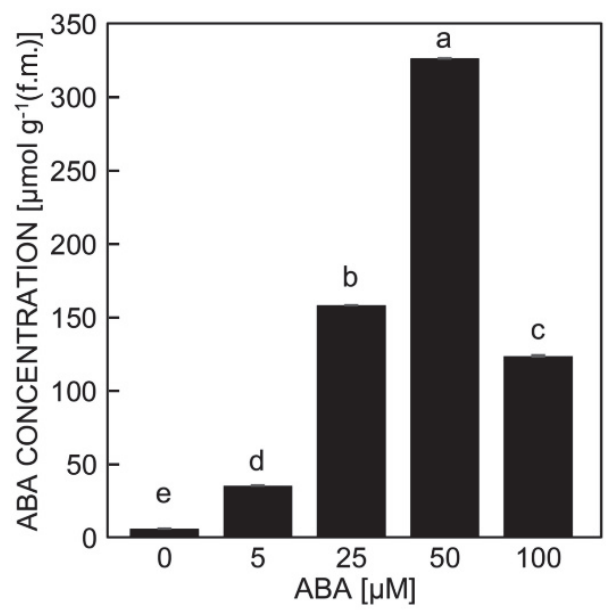

Fig. 4. Effect of different concentrations of $\mathrm{ABA}$ on endogenous ABA in Melissa officinalis shoots one week after application. Means $\pm \mathrm{SDs}, n=3$. Values followed by different letters are significantly different at $P \leq 0.05$ according to LSD test.

Generally, treatment by various types of elicitors induces a rapid increase in the endogenous ABA content (Gagne et al. 2011, Hao et al. 2012, Villalobos-Gonzalez et al. 2016, Kuyyogsuy et al. 2018). Therefore, both the content of endogenous ABA and the expression of pivotal gene associated with the ABA biosynthetic pathway $(N C E D)$ increased in the shoot cultures of lemon balm treated with ABA. The ABA content in shoots was increased within $7 \mathrm{~d}$ after $\mathrm{ABA}$ application and its maximum was detected in the shoots treated with $50 \mu \mathrm{M}$ ABA. Increase in the expression of $N C E D$ leads to an increase in the ABA content (Castellarin et al. 2016) also in response to environmental stresses (Agusti et al. 2007, Kuyyogsuy et al. 2018). In our study, the expression of $N C E D$ was up-regulated in the plants treated with $50 \mu \mathrm{M}$ ABA compared to the control. Results showed that although expression of NCED was not increased in the shoots treated with $5 \mu \mathrm{M}$ ABA, the endogenous ABA was increased in the shoots, suggesting that the increase could be due to the decreased catabolism of this hormone. Our finding revealed that the ABA application could induce an increase in the endogenous ABA together with via up- regulation of the NCED gene expression. Thus, it could be suggested that the exogenous ABA stimulated ABA biosynthesis through increasing expression of NCED.

The applied ABA can also trigger the generation of $\mathrm{H}_{2} \mathrm{O}_{2}$ in the plant cells or tissues (Hu et al. 2010, Ye et al. 2011). ROS, especially $\mathrm{H}_{2} \mathrm{O}_{2}$ and $\mathrm{O}_{2}{ }^{-}$, are involved in the ABA signaling pathway, thus, ABA increases ROS accumulation which leads to changes in gene expression and in metabolism. After foliar applications of ABA antioxidative properties of cells might be up-regulated by the increase in the content of phenolics and flavonoids (Ibrahim and Jaafar 2013). Accumulation of ROS in plants is generally attributed to several possible sources, including plasma membrane-localized NAD(P)H oxidase, oxalate oxidase, apoplastic peroxidase, and amino oxidase (Bolwell 1999). Previous studies have found that the $\mathrm{H}_{2} \mathrm{O}_{2}$ generated by NADPH oxidase encoded by $\mathrm{RBOH}$ plays an important role in plant responses to biotic and abiotic stresses. The results of the present study indicated that the expression of $\mathrm{RBOH}$, which is a key player in controlling $\mathrm{H}_{2} \mathrm{O}_{2}$ accumulation, was significantly up-regulated by ABA application.

Phenylalanine ammonia lyase (PAL) is known as a key enzyme in RA biosynthetic pathway (Dong et al. 2010). Several studies have revealed that exogenous ABA could induce the activation of PAL (Hao et al. 2012). The results of the present study revealed that exogenous ABA induced the activation of PAL and synthesis of RA in the shoots of lemon balm. Here, we reported that ABA induced the accumulation of RA and phenolic compounds. Our findings are consistent with those of the previous studies on other plant species which reported that the content of RA and phenolic compounds was increased by application of biotic and abiotic elicitor (Yan et al. 2006, Bauer et al. 2009, Kim et al. 2013, Ejtahed et al. 2015). In this study, ABA was used as an elicitor to examine the relationship between the expression of rate-limiting enzymes in the two RA biosynthesis pathways and accumulation of RA in the shoot cultures. The expressions of PAL, TAT, and RAS genes were significantly up-regulated as the result of ABA treatment. Expressions of these genes are correlated with the RA content in several plants (Weitzel and Petersen 2010, Doring et al. 2014). These results suggested that both the PAL- and TAT-derived pathways were induced by ABA to increase RA accumulation in the shoot cultures of lemon balm.

In summary, ABA application could effectively induce RA accumulation by the induction of the PAL activity, as well as by the up-regulation of $P A L, T A T$, and $R A S$ genes. In addition, the up-regulated expression of $N C E D$ gene by ABA treatment is correlated with the enhancement of ABA content. In this study, ABA not only mediates the accumulation of endogenous ABA, but also controls the production of $\mathrm{H}_{2} \mathrm{O}_{2}$ by changing the expression pattern of $\mathrm{RBOH}$ gene. 


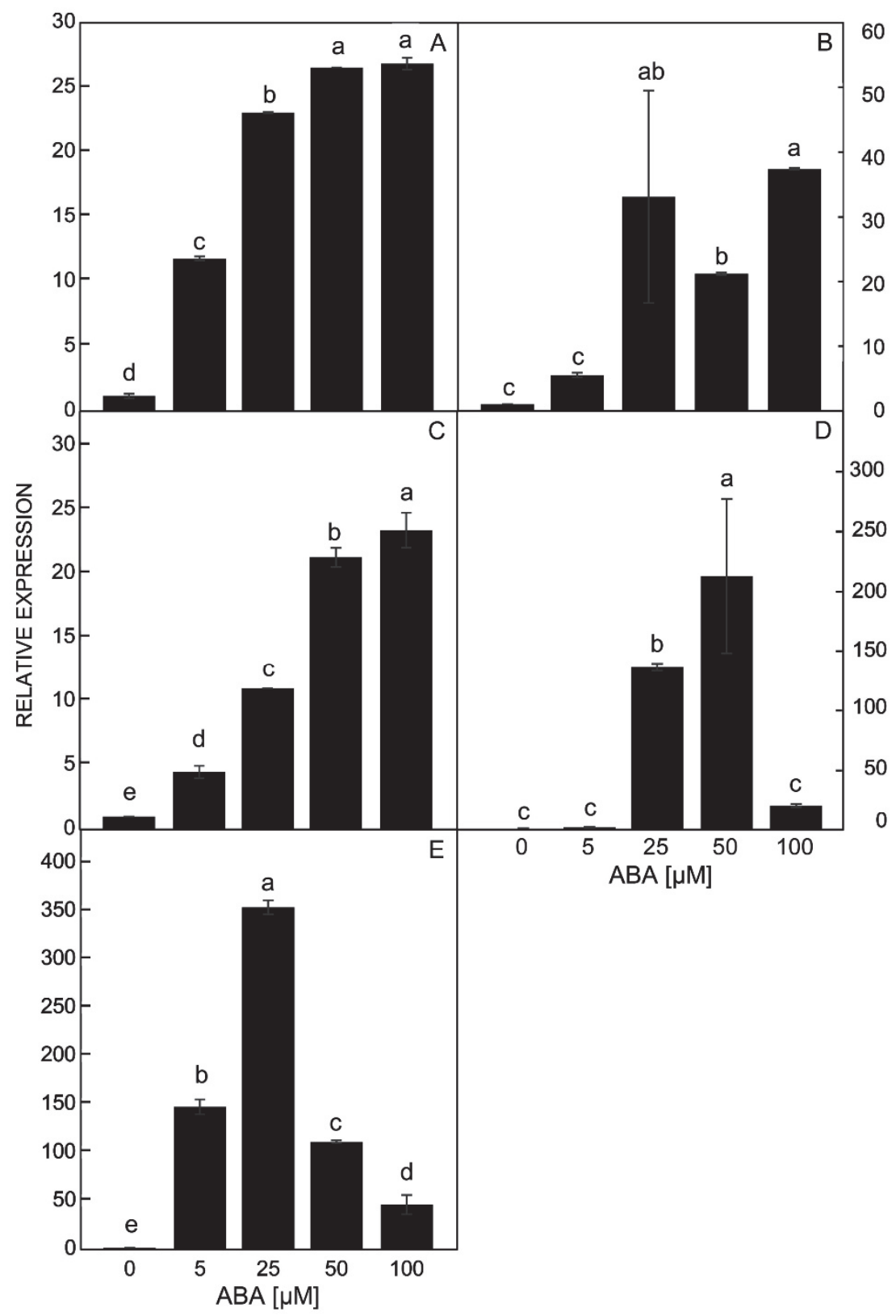

Fig. 5. Relative transcriptions of PAL (A), TAT $(B), R A S(C), N C E D(D)$, and RBOH (E) genes in Melissa officinalis shoots treated with different concentrations of ABA in relation to the housekeeping gene actin. Means $\pm \mathrm{SDs}, n=3$. Values followed by different letters are significantly different at $P \leq 0.05$ according to LSD test.

\section{References}

Abell, C.W., Shen, R.S.: Phenylalanine ammonia-lyase from the yeast Rhodotorula glutinis. -Methods Enzymol. 142: 242253, 1987.

Agusti, J., Zapater, M., Iglesias, D.J., Cercos, M., Tadeo, F.R., Talon, M.: Differential expression of putative 9-cisepoxycarotenoid dioxygenases and abscisic acid accumulation in water stressed vegetative and reproductive tissues of citrus. - Plant. Sci. 172: 85-94, 2007.

Alexieva, V., Sergiev, I., Mapelli, S., Karanov, E.: The effect of drought and ultraviolet radiation on growth and stress markers in pea and wheat. - Plant. Cell Environ. 24: 13371344, 2001.

Bauer, N., Kiseljak, D., Jelaska, S.: The effect of yeast extract and methyl jasmonate on rosmarinic acid accumulation in Coleus blumei hairy roots. - Biol. Plant. 53: 650-656, 2009.

Bolwell, G.P.: Role of active oxygen species and NO in plant defence responses. - Curr. Opin. Plant Biol. 2: 287-294, 1999.

Castellarin, S.D., Gambetta, G.A., Wada, H., Krasnow, M.N., 
Cramer, G.R., Peterlunger, E., Shackel, K.A., Matthews, M.A..: Characterization of major ripening events during softening in grape: turgor, sugar accumulation, abscisic acid metabolism, colour development, and their relationship with growth. - J. exp. Bot. 67: 709-722, 2016.

Dong, J., Wan, G., Liang, Z.: Accumulation of salicylic acidinduced phenolic compounds and raised activities of secondary metabolic and antioxidative enzymes in Salvia miltiorrhiza cell culture. - Biotechnoogy. 148: 99-104, 2010.

Doring, A.S., Pellegrini, E., Campanella, A., Trivellini, A., Gennai, C., Petersen, M., Nalia, C., Lorenzini, G.: How sensitive is Melissa officinalis to realistic ozone concentrations. - Plant. Physiol. Biochem. 74: 156-164, 2014.

Ejtahed, R.S., Radjabian, T., Hoseini-Tafreshi, S.A.: Expression analysis of phenylalanine ammonia lyase gene and rosmarinic acid production in Salvia officinalis and Salvia virgata shoots under salicylic acid elicitation. - Appl. Biochem. Biotechnol. 176: 1846-1858, 2015.

Ellis, B.E., Towers, G.H.: Biogenesis of rosmarinic acid in Mentha. - Biochem. J. 118: 291-297, 1970.

Gagne, S., Cluzet, S., Merillon, J.M., Geny, L.: ABA initiates anthocyanin production in grape cell cultures. - J. Plant Growth Regul. 30: 1-10, 2011.

Hao, G., Ji, H., Li, Y., Shi, R., Wang, J., Feng, L., Huang, L.: Exogenous $\mathrm{ABA}$ and polyamines enhanced salvianolic acids contents in hairy root cultures of Salvia miltiorrhiza Bunge f. alba. - Plant Omics 5: 446-452, 2012.

Hedden, P., Thomas, S.G.: Plant Hormone Signaling. Blackwell, Oxford 2006.

Hu, X.L., Liu, R.X., Li, Y.H., Wang, W., Tai, F.J., Xue, R.L., Li, C.H.: Heat shock protein 70 regulates the abscisic acidinduced antioxidant response of maize to combined drought and heat stress. -Plant Growth Regul. 60: 225-235, 2010.

Ibrahim, M.H., Jaafar, H.Z.E.: Abscisic acid induced changes in production of primary and secondary metabolites, photosynthetic capacity, antioxidant capability, antioxidant enzymes and lipoxygenase inhibitory activity of Orthosiphon stamineus Benth. - Molecules 18: 7957-7976, 2013.

Jabs, T.: Reactive oxygen intermediates as mediators of programmed cell death in plants and animals. - Biochem. Pharm. 57: 231-245, 1999.

Kelen, M., Demiralay, E.C., Sen, S., Özkan, G.: Separation of abscisic acid, indole-3-acetic acid, gibberellic acid in $99 \mathrm{R}$ (Vitis berlandieri, Vitis rupestris) and rose oil (Rosa damascena) by reversed phase liquid chromatography. Turk. J. Chem. 28: 603-610, 2004.

Kim, Y.B., Kim, J.K., Uddin, M.R., Xu, H., Park, W.T., Tuan, P.A., Li, X., Chung, E., Lee, J.H., Park, S.U.: Metabolomics analysis and biosynthesis of rosmarinic acid in Agastache rugosa Kuntze treated with methyl jasmonate. - PLoS ONE 8: e64199, 2013.

Kuyyogsuy, A., Deenamo, N., Khompatara, K., Ekchaweng, K., Churngchow, N.: Chitosan enhances resistance in rubber tree (Hevea brasiliensis), through the induction of abscisic acid (ABA). - Physiol. mol. Plant. Pathol. 102: 67-78, 2018.

Liang, Z., Ma, Y., Xu, T., Cui, B., Liu, Y., Guo, Z., Yang, D. Effects of abscisic acid, gibberellin, ethylene and their interactions on production of phenolic acids in Salvia miltiorrhiza Bunge hairy roots. - PLoS ONE 8: e72806, 2013.

Ma, P., Liu, J., Zhang, C., Liang, Z.: Regulation of water-soluble phenolic acid biosynthesis in Salvia miltiorrhiza Bunge. -
Appl. Biochem. Biotechnol. 170: 1253-1262, 2013.

Matsuno, M., Nagatsu, A., Ogihara, Y., Ellis, B.E., Mizukami, H.: CYP98A6 from Lithospermum erythrorhizon encodes 4coumaroyl-4'-hydroxyphenyllactic acid 3-hydroxylase involved in rosmarinic acid biosynthesis. - FEBS Lett. 514: 219-224, 2002.

Mizukami, H., Ogawa, T., Ohashi, H., Ellis, B.E.: Induction of rosmarinic acid biosynthesis in Lithospermum erythrorhizon cell suspension cultures by yeast extract. - Plant. Cell. Rep. 11: 480-483, 1992.

Murashige, T., Skooge, F.: A revised medium for rapid growth and bio assays with tobacco tissue culture. - Physiol Plant. 15: 473-497, 1962.

Murcia, G., Fontana, A., Pontin, M., Baraldi, R., Bertazza, G., Piccoli, P.N.: ABA and $\mathrm{GA}_{3}$ regulate the synthesis of primary and secondary metabolites related to alleviation from biotic and abiotic stresses in grapevine. - Phytochemistry 135: 3452, 2017.

Özturk, M., Duru, M.E., Ince, B., Harmandar, M., Topcu, G.: A new rapid spectrophotometric method to determine the rosmarinic acid level in plant extracts. - Food. Chem. 123: 1352-1356, 2010

Petersen, M.: Characterization of rosmarinic acid synthase from cell cultures of Coleus blumei. - Phytochemistry 30: 28772881, 1991

Petersen, M., Simmonds, M.S.J.: Molecules of interest: rosmarinic acid. - Phytochemistry. 62: 121-125, 2003.

Rodriguez-Gacio, M.C., Matilla-Vazquez, M.A., Matilla, A.J.: Seed dormancy and ABA signaling: the breakthrough goes on. - Plant. Signal. Behav. 4: 1035-1049, 2009.

Singleton, V., Rossi, J.A.: Colorimetry of total phenolics with phosphomolybdic-phosphotungstic acid reagents. - Amer. J. Enol. Viticult. 16: 144-158, 1965.

Thompson, A.J., Mulholland, B.J., Jackson, A.C., McKee, J.M., Hilton, H.W., Symonds, R.C., Sonneveld, T., Burbidge, A., Stevenson, P., Taylor, I.B.: Regulation and manipulation of ABA biosynthesis in roots. - Plant. Cell Environ. 30: 67-78, 2007.

Ton, J., Flors, V., Mauch-Mani, B.: The multifaceted role of ABA in disease resistance. - Trends Plant. Sci. 14: 310-317, 2009.

Vagner, M., Vondrakova, Z., Strandova, Z., Eder, J., Machackova, I.: Endogenous levels of plant growth hormones during early stages of somatic embryogenesis of Picea abies. - Adv. hort. Sci. 12: 11-18, 1998.

Villalobos-Gonzaalez, L., Pena-Neira, A., Ibanez, F., Pastenes, C.: Long-term effects of abscisic acid (ABA) on the grape berry phenylpropanoid pathway: gene expression and metabolite content. - Plant. Physiol. Biochem. 105: 213-223, 2016.

Weitzel, C., Petersen, M.: Enzymes of phenylpropanoid metabolism in the important medicinal plant Melissa officinalis L. - Planta 232: 731-742, 2010.

Yan, Q., Shi, M., Ng, J., Wu, J.Y.: Elicitor-induced rosmarinic acid accumulation and secondary metabolism enzyme activities in Salvia miltiorrhiza hairy roots. - Plant. Sci. 170: 853-858, 2006.

Ye, N., Zhu, G., Liu, Y., Li, Y., Zhang, J.: ABA controls $\mathrm{H}_{2} \mathrm{O}_{2}$ accumulation through the induction of OsCATB in rice leaves under water stress. - Plant cell. Physiol. 52: 689-698, 2011.

Zhang, J., Jia, W., Yang, J., Ismail, A.M.: Role of ABA in integrating plant responses to drought and salt stresses. Field Crops Res. 97: 111 - 119, 2006. 